$\mathbf{R}_{\text {ESEA }} \mathbf{R C H}$ A RTICLE

\section{Histomorphological and histochemical studies on vagina of oviduct in Japaneis quails}

\author{
P. N. Thakur, P. J. Kapadnis ${ }^{1}$ and N. M. Karad ${ }^{1}$
}

Members of the Research Forum Associate Author :

${ }^{1}$ Department of Veterinary Anatomy, College of Veterinary and Animal Sciences, Parbhani (M.S.) India

AUTHOR FOR CORRESPONDENCE : P. N. Thakur,

Department of Veterinary Anatomy, College of Veterinary and Animal Sciences, Parbhani (M.S.) India

Email : pravin_thakur75@

rediffmail.com
Abstract : The mucosa of each vagina presented lamina epithelialis, lamina propria and lamina mucosae. The mucosa was thrown into folds viz., primary and secondary folds. The number of folds were significantly reduced in vaginal part of oviduct. The lamina epithelialis presented pseudostratified columnar ciliated epithelium in vagina in both the groups of quail.

Key words : Histomorphology, Histochemistry, Vagina oviduct, Japanese quail

How to cite this paper: Thakur, P.N., Kapadnis, P.J. and Karad, N.M. (2019). Histomorphological and histochemical studies on vagina of oviduct in Japaneis quails. Vet. Sci. Res. J., 10(1) : 17-21, DOI : 10.15740/HAS/VSRJ/10.1/17-21. Copyright@2019: Hind Agri-Horticultural Society.

Paper History : Received : 06.02.2019; Revised : 15.03.2019; Accepted : 22.03 .2019 